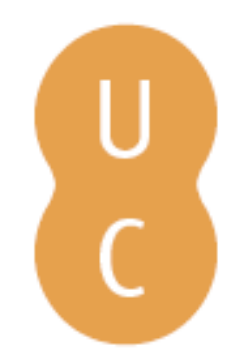

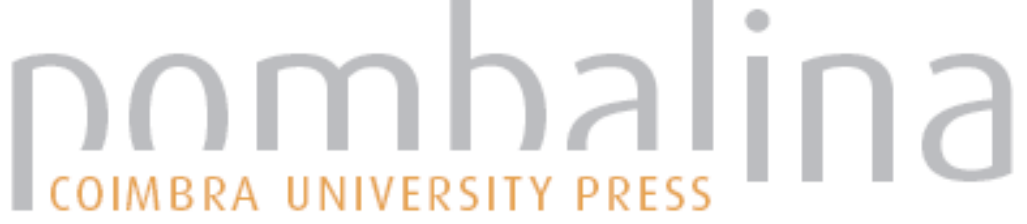

\section{A Biblioteca Geral, alegoria da Universidade}

Autor(es): $\quad$ Bernardes, José Augusto Cardoso

Publicado por: Imprensa da Universidade de Coimbra

URL

persistente: URI:http://hdl.handle.net/10316.2/36988

DOI: $\quad$ DOI:http://dx.doi.org/10.14195/978-989-26-1045-0_17

Accessed : $\quad$ 26-Apr-2023 12:26:35

A navegação consulta e descarregamento dos títulos inseridos nas Bibliotecas Digitais UC Digitalis, UC Pombalina e UC Impactum, pressupõem a aceitação plena e sem reservas dos Termos e Condições de Uso destas Bibliotecas Digitais, disponíveis em https://digitalis.uc.pt/pt-pt/termos.

Conforme exposto nos referidos Termos e Condições de Uso, o descarregamento de títulos de acesso restrito requer uma licença válida de autorização devendo o utilizador aceder ao(s) documento(s) a partir de um endereço de IP da instituição detentora da supramencionada licença.

Ao utilizador é apenas permitido o descarregamento para uso pessoal, pelo que o emprego do(s) título(s) descarregado(s) para outro fim, designadamente comercial, carece de autorização do respetivo autor ou editor da obra.

Na medida em que todas as obras da UC Digitalis se encontram protegidas pelo Código do Direito de Autor e Direitos Conexos e demais legislação aplicável, toda a cópia, parcial ou total, deste documento, nos casos em que é legalmente admitida, deverá conter ou fazer-se acompanhar por este aviso.

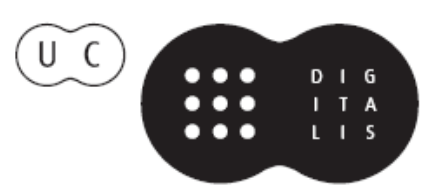



Tendo como pano de fundo as Comemorações dos seus 500 anos, a Biblioteca Geral da Universidade de Coimbra organizou um Congresso Internacional subordinado ao tema "A Biblioteca da Universidade: permanência e metamorfoses", que teve lugar nos dias 16, 17 e 18 de janeiro de 2014, no auditório da Reitoria da Universidade de Coimbra.

O objetivo maior desta reunião científica foi o de refletir sobre o presente e o futuro das bibliotecas que servem públicos universitários. Numa outra vertente, procurou chamar-se a atenção para a importância de que a Biblioteca se reveste, tendo em vista o progresso do conhecimento técnico e científico. Por último, o Congresso pretendeu instituir-se como oportunidade de reflexão prospetiva e como lugar de encontro entre as sensibilidades de todos os que trabalham profissionalmente com livros e com outros suportes de natureza bibliográfica.

Nesse sentido, foram apresentadas Conferências, Mesas Redondas e sessões de Testemunhos em torno de temas como o valor das bibliotecas universitárias, a biblioteca universitária em contexto; as mudanças e os desafios; a biblioteca universitária e a sociedade da informação e conhecimento; o impacto do acesso aberto na comunidade científica, e as bibliotecas digitais. 


\section{José Augusto CARdoso Bernardes}

Universidade de Coimbra

University of Coimbra

A BIBLIOTECA GERAL, ALEGORIA DAUNIVERSIDADE

ThE MAIN LibRARY, AN Allegory OF THE UNiversity

RESUMO: Mais do que um equipamento entre muitos outros, a Biblioteca universitária constitui um espaço de estudo e de pesquisa, onde é possível congregar pessoas e saberes. Quando se trata de uma Biblioteca Geral, esse potencial estende-se mesmo a toda a Universidade, desempenhando um papel decisivo no contacto entre as diferentes disciplinas que são investigadas e ensinadas no campus. Evoluindo desde a Casa da Livraria (de que existe notícia certa desde 1513) até aos nossos dias, a Biblioteca Geral da Universidade de Coimbra é hoje também chamada a promover o encontro com o livro, concebido enquanto unidade discursiva complexa, contrariando a tendência para a recolha de informação fragmentária e muitas vezes não validada, que se instalou no meio estudantil, através de processos de reprodução avulsa, incluindo o espaço cibernético. No cumprimento destas duas importantes missões, a Biblioteca serve assim os ideais de uma Universidade abrangente, no plano do conhecimento e indutora do esforço perseverante, no plano ético.

ABSTRACT: Rather than serving as just one of many facilities, the university library is a space for study and research which brings people and knowledge together. In the case of a main library, this potential extends to the entire university and it plays a decisive role in establishing contacts between the different disciplines that are taught and are the subject of research on the campus. Having developed from the Casa da Livraria (documented since 1513) to the present day, the University of Coimbra Main Library is nowadays also called upon to foster contact with books, understood as complex discursive units, thus countering the trend towards gathering fragmented and often unvalidated information that has instilled itself in the student population through the use of separate reproduction procedures, including those in cyberspace. In fulfilling these two important missions, the library serves the ideals of a university that is comprehensive in terms of knowledge and is also a catalyst for sustained effort, on an ethical level. 
1. Em Coimbra, existe um edifício com quase três séculos ${ }^{1}$. Foi concebido como biblioteca mas, nos últimos anos, transformou-se também num lugar de atração turística, sendo visitado por mais de 200 mil pessoas em cada ano. A grande maioria sente-se sobretudo tocada pelo aparato visual: os dourados que recobrem as colunas e envolvem o retrato de D. João V, o monarca que dá nome à Biblioteca e que se deixa contemplar em pose de serena majestade. Outros deixam-se impressionar pela grande concentração de madeira entalhada ou então, elevando a vista, reparam nas figuras femininas e nas inscrições latinas dos tetos. Existe também a (considerável) parcela daqueles que se contentam em saber dos morcegos. Morcegos numa biblioteca? Existem realmente ou trata-se apenas de um mero expediente de marketing? Quando lhes garantimos que os mamíferos habitam aquele espaço desde há séculos, repartindo-se por duas espécies diferentes que se acolhem por detrás das estantes, logo perguntam quantos são, se comem apenas as larvas e as borboletas que atacam os livros ou se precisam de vir cá fora para variar a ementa. Por fim, há ainda visitantes que perguntam pelos livros: querem saber se ainda são lidos e, sobretudo, se valem todos muito dinheiro.

Com tantos focos de curiosidade, os turistas esquecem que se encontram numa biblioteca universitária ou seja, estão dentro de um edifício que serve para guardar os livros que, ao longo dos séculos, serviram de base de trabalho para investigadores, professores e estudantes. Apurando a atenção, os visitantes podem até verificar que faltam alguns volumes nas estantes. O mais provável é estarem a ser objeto de restauro; mas também podem estar a ser lidos nesse preciso momento, num outro lugar. De facto, embora no edifício se encontrem apenas livros antigos (muitos deles escritos em latim e todos editados até ao ano de 1801) há ainda

1 Refiro-me especificamente ao edifício da Casa da Livraria, vulgarmente conhecido por Biblioteca Joanina, construído entre 1717 e 1728. Com base num documento que certifica o seu funcionamento em 12 de fevereiro de 1513, a Biblioteca Geral da Universidade de Coimbra acaba de celebrar 500 anos de existência. Sobre a história acumulada ao longo desses cinco séculos, veio recentemente a público um valioso trabalho, da autoria conjunta de três bibliotecários, sob coordenação de António Eugénio Maia Amaral. Em si mesma, também a Biblioteca Joanina foi recentemente objeto de um trabalho inovador, conjugando texto e fotografia, da responsabilidade dos Doutores Carlos Fiolhais e Paulo Mendes. 
leitores que os procuram. Em boa verdade, raro é o dia em que os funcionários não têm que percorrer a distância entre essa biblioteca antiga e um outro edifício mais recente (este inaugurado em 1962), transportando pesados volumes para os colocar na mesa de leitores interessados.

Mas o edifício a que me refiro não serve apenas para acomodar uma parte dos livros antigos da Universidade. Para além dessa função mais visível, ele é também portador de uma doutrina para a instituição, vista no seu todo. Exatamente: a biblioteca a que me refiro foi erigida entre 1717 e 1728, substituindo outras construções mais antigas e dispersas, que já não reuniam condições de segurança. A doutrina dirige-se à universidade, que é, como sabemos, uma das mais antigas que vem atravessando os séculos, sem perda de eficácia ou de prestígio.

A função original (a de guardar os livros ordenadamente) quase faz esquecer essa outra mensagem. Mas basta conhecer um pouco da história da universidade para poder "escutar" e compreender a apologia que surge inscrita nessa portentosa "casa falante". Foi decerto a pensar nos estudantes e professores daquele tempo concreto que se construiu a Casa da Livraria. Mas a oportunidade do que é dito nada perde quando fazemos a transposição para o século XXI. Pelo contrário: ficamos com a sensação de que, passados trezentos anos, a mensagem em apreço conserva toda a pertinência.

Olhemos então para os tetos e reparemos nos "argumentos" que lá foram gravados, de forma sequencial e articulada. Logo na primeira sala, diz-se que o saber da biblioteca vem dos quatro cantos do mundo e não apenas da Europa, onde então se concentrava a esmagadora maioria das tipografias. Quase não é preciso fazer notar que essa mensagem envolve uma visão atualíssima da biblioteca e do conhecimento, que, para além dos materiais impressos, conhece muitos outros tipos de suporte. Diz-se depois, na segunda sala, que a universidade não é apenas uma casa de saber. Longe disso. Necessita muito de conjugar a produção do conhecimento com a observância de princípios morais: a Honra, a Virtude, a Fama, a Fortuna. Finalmente, na terceira sala, o lugar central é ocupado pela Enciclopédia, cabendo os lugares circundantes a quatro Musas que reúnem os saberes professados na Universidade: Sacra Pagina (Teologia e 
Cânones), Astrea (Leis), Natvra (Filosofia, Medicina e Matemática) e Aros (Gramática e Retórica). Ou seja, os saberes particulares de cada faculdade só se transformam em sabedoria se contribuírem para um outro tipo de conbecimento: o conbecimento que justamente não se resume a uma mera soma mas resulta da relação produtiva entre as diferentes parcelas. Como é difícil, ainda hoje, entender e aceitar esta verdade, plasmada naquele edifício de Coimbra!

O propósito da mensagem não deixa lugar para dúvidas: trata-se de superar a visão medieval traduzida na conjunção de escolas, mestres e estudantes. A forma de superação consiste na existência de um ponto central, sempre figurado sob a forma de triunfo: biblioteca, universidade e enciclopédia são variações desse mesmo centro subordinante.

Como há pouco dizia, trata-se de um discurso datado, que se compreende em função dos fundamentos estético-filosóficos que antecipam o Iluminismo. Vista no seu conjunto, porém, essa mensagem constitui a resposta a uma das necessidades mais constantes da universidade de qualquer tempo: falo da existência de um ethos agregador, capaz de construir uma identidade que seja, ao mesmo tempo, compósita mas organizada. A observância deste princípio nunca foi fácil e, como bem sabemos, essa dificuldade é responsável por boa parte das tensões que ainda hoje se verificam nos órgãos de governo da universidade. Por orgulho ou por fraqueza, cada uma das culturas ou das microculturas que habitam a Academia procura desmentir a paridade espelhada naqueles tetos, em nome de uma qualquer supremacia, que garanta mais prestígio, mais poder e mais dinheiro.

Não estamos perante um acidente de conjuntura. Bem pelo contrário: o tipo de identidade a que me refiro foi e continua a ser um problema maior da instituição universitária. Pode parecer surpreendente mas, no século XVIII, a resposta maior para este problema parecia ser só uma: a biblioteca ${ }^{2}$.

2 Sobre a afirmação das bibliotecas enquanto locus central da universidade, veja-se: BARBIER, Frédéric - Histoire des bibliothèques: d'Alexandrie aux bibliothèques virtuelles. Paris: Armand Colin, 2013, cap. 5, 6 e 7, cobrindo justamente o período que medeia entre 1547 e 1789. 
Pela sua abrangência e também pelo seu prestígio só a biblioteca era reconhecida como espaço necessário a todos, só ela poderia contribuir para apaziguar tensões, neutralizando ou minorando os efeitos das guerras de cultura que se verificavam no seio da universidade.

Assim se explicam, desde logo, os fundamentos apresentados a D. João V pelo Reitor da época quando quis justificar a construção de um edifício que servia para proclamar a unidade do saber. Já não bastava acomodar, em estantes contíguas, os volumes que versavam as diferentes matérias, prendendo-os com cadeados para que não fossem roubados ou deslocados da sua ordem. A intenção era mais ambiciosa e visava idealizar e glorificar a universidade enquanto organismo global e metafísico. Quando, com percentagens variáveis de temor e de entusiasmo, se referem os desafios que hoje se colocam às bibliotecas universitárias, é justo recordar este outro desafio com que as mesmas foram confrontadas há três séculos atrás: a de se assumirem como sinédoque ou alegoria da própria universidade ${ }^{3}$.

2. Cinco décadas mais tarde, a chamada reforma pombalina haveria de trazer a Coimbra uma mudança profunda que se traduziu na valorização dos novos saberes, de base experiencial e de alcance cosmopolita ${ }^{4}$.

3 A carta datada de 8 de junho de 1716, foi remetida pelo Reitor Nuno da Silva Teles, solicitando autorização para a compra da biblioteca do Dr Francisco Barreto. Logo depois, em 31 de julho do mesmo ano, o Reitor envia nova carta, solicitando autorização para construir um edifício. Os documentos em apreço foram já objeto da análise de alguns historiadores da universidade. Vejam-se, em concreto, as considerações que sobre eles teceu Fernando Taveira da Fonseca em: FONSECA, Fernando Taveira da - A Universidade de Coimbra (17001771). Estudo social e económico. Coimbra: Por ordem da Universidade, 1995, pp. 789-90.

${ }^{4}$ Refiro-me à Reforma da Universidade iniciada em 1770 e consumada com a outorga dos novos Estatutos, em 28 de Setembro de 1772. Em síntese bem expressiva, Maria Eduarda Cruzeiro refere-se desta forma à natureza e ao impacto da Reforma: "Gesto divino de um poder absoluto, para mais "iluminado", a reforma cai sobre a Universidade como um raio, com os seus poderes complementares de destruição e de revelação. É como se não devesse ficar pedra sobre pedra, como se só sobre as ruínas da cidade maldita se pudesse edificar a nova Jerusalém. E esta foi, literalmente, uma das missões do marquês: não foram só os mestres antigos que se substituíram por outros; não foram só as estruturas administrativas, viciadas, mas pouco visíveis, que deram lugar a outras, racionais; foram muros e paredes que punitiva e purificadoramente se arrasaram como símbolos de um poder usurpador que sugara a vida da instituição e a envilecera, para fazer surgir novos espaços e novas divisões, que na nova era deveriam ser uma marca material, e também simbólica, de uma nova existência. É um facto que a reforma para se tornar efectiva implicava grandes 
A prioridade era agora a construção de laboratórios, gabinetes experimentais, anfiteatros ou jardins, que servissem de mostruário e guarida de espécies exóticas. Essa lógica setorial originou também a fundação das bibliotecas especializadas (Botânica, Ciências Jurídicas, Astronomia, etc.). Algumas das que foram então criadas em Coimbra chegaram aos nossos dias notavelmente robustecidas $^{5}$. Ainda hoje, a questão está longe de se encontrar resolvida: as lógicas da especialização e da abrangência vêm-se sucedendo uma à outra, quase sempre numa clima de radicalidade. Isto sucede na Universidade, em geral; mas ocorre também no próprio seio das diferentes culturas que a integram, originando "microculturas" especialmente aguerridas ${ }^{6}$.

Dois séculos mais tarde, um outro tipo de mudança chegaria à cidade do Mondego, atingindo, desta vez, sobretudo, os espaços físicos da Universidade. Falo de uma profunda reconversão infraestrutural da cidade universitária que data das décadas de 40 e 50 do século XX. Essa mudança traduziu-se na construção de várias faculdades e viria a incluir também a adaptação do espaço para a nova biblioteca. Previa-se então que esse novo edifício pudesse durar 50 anos e acolher cerca de meio milhão de monografias. O edifício a que agora me refiro resultou do ajustamento da antiga Faculdade de Letras mas era praticamente novo, sendo justo reconhecer que ficou provido de tudo o que de melhor existia: aquecimento central, sala para mais de 200 leitores, mobiliário especialmente desenhado, recintos nobres como o salão de São Pedro,

alterações, entre as quais se contavam a adaptação e a criação de estabelecimentos anexos às Faculdades "naturais», como o Dispensatório Farmacêutico, o Laboratório Químico, o Teatro Anatómico, o Gabinete de Física, dito "das Máquinas», etc. A verdade, também, é que a esta necessidade material, perfeitamente justificada, se procurava dar uma outra dimensão, pela qual se reforçava simbolicamente a acção reformadora. Chegara a vez da Universidade e o voluntarismo pombalino, sustentado pela força do Estado absoluto que se consolidava, devia agora alterar-lhe a face." (CRUZEIRO, Maria Eduarda - A reforma pombalina na história da Universidade. Análise Social. ISSN 0003-2573. 24:100 (1988), p. 182).

5 Para além de possuírem um acervo numeroso e atualizado, algumas bibliotecas setoriais são ainda detentoras de uma forte componente de livro antigo. É, entre outros, o caso das Bibliotecas de Matemática, da Faculdade de Direito ou de Medicina, agora associada a áreas contíguas, que, no seu conjunto, formam a Biblioteca das Ciências da Saúde.

6 Refiro-me concretamente às três culturas identificadas pelo Professor Jerome Kagan no seu já célebre livro: KAGAN, Jerome - The three cultures: Natural Sciences, Social Sciences and the Humanities in the 21 st Century. Cambridge: Cambridge University Press, 2009. 
sala de reservados e um quadro de funcionários que chegou a rondar a centena, entre bibliotecários e contínuos, como então se designava o pessoal menos graduado. Esta estrutura servia os 1770 estudantes que, na altura, se encontravam matriculados na Universidade (o número de inscritos ronda hoje os $27 \mathrm{mil}$ ).

3. Preservar o acervo que se encontra à sua guarda, disponibilizá-lo aos interessados, (presencial e virtualmente), atualizar esse mesmo acervo, descobrir novas formas de atrair estudantes ou facilitar a tarefa de quem investiga ao mais alto nível continuam a ser as preocupações mais importantes de quem trabalha numa biblioteca universitária. Por se tratar de missões discretas, nem sempre são devidamente reconhecidas. Basta uma pequena contrariedade (um original que, por motivos de segurança, já não pode vir à consulta, por exemplo) para que o utente lavre uma queixa no Livro de Reclamações ou escreva uma carta para um jornal, dando repercussão pública à sua indignação. Pouco podemos fazer em tais circunstâncias, a não ser examinar o nosso procedimento para ver se ele pode ser melhorado. Podemos e devemos ainda tentar ler essa atitude à luz da idiossincrasia própria do investigador, em cujo trabalho prevalece o gosto mas também a ansiedade e o sacrifício mal recompensado.

Acomodar livros e outros documentos, chamar a atenção para eles e proporcioná-los a quem os procura em condições de segurança e comodidade representa uma vocação perene, que está para além das mudanças tecnológicas.

Mas a missão de uma biblioteca universitária não pode continuar a cumprir-se da mesma forma. Os estudantes que hoje chegam à Universidade pertencem já à categoria dos born digital, os mesmos que praticam a leitura oblíqua e descontinuada em ecrãs, limitada a segmentos de 15 minutos.

Essa nova realidade coloca desafios especialmente exigentes aos professores (terão os bibliotecários consciência dos desafios dramáticos que hoje se enfrentam nos anfiteatros da universidade?). Mas essa mesma realidade não poupa os bibliotecários, que se veem obrigados a lidar com 
os mesmos alunos (terão os professores consciência das dificuldades que daí resultam para quem trabalha nas bibliotecas?).

Deve a Biblioteca resignar-se com a situação e transformar-se num learning center indiferenciado? Deve preservar-se (ou esconder-se), convertendo-se num santuário de eruditos? Ou deve resistir, teimando na sua tarefa educativa? Nesse caso, pode ainda perguntar-se: até que ponto deve ir esse esforço de adaptação?

Não conheço respostas fáceis e universais para perguntas como estas. A única resposta que arrisco consiste em afirmar que, tal como a universidade, no seu todo, também a biblioteca que serve o público académico deve ter a coragem de contrariar algumas das tendências que a anomia das sociedades vem favorecendo.

É nesse plano de resistência flexível que prefiro situar-me. Refiro, em primeiro lugar, que, tal como no início do século XVIII, a biblioteca pode ainda servir como alegoria (ou cidadela) da própria universidade, no seu todo. Enquanto estrutura complexa, dotada de uma história que pode abranger vários séculos, como é o caso de Coimbra, a universidade continua a necessitar vitalmente de fatores de agregação. Ora, nas universidades modernas não abundam os fatores desse tipo, com prejuízo da multidisciplinaridade sadia e fecunda. Os próprios órgãos de governo da universidade, que, em princípio, parecem talhados para favorecer a coesão entre os diferentes saberes, pouco conseguem fazer para evitar o desconhecimento que subsiste entre as diferentes faculdades, favorecendo a desconfiança que, como bem sabemos, se acentua em momentos de urgência orçamental. Na falta de outras oportunidades de contacto, tanto no plano do ensino como no da investigação, a Biblioteca Geral tem, ainda hoje, condições privilegiadas para continuar a ser um polo de convergência, ou seja, uma casa onde toda a comunidade académica pode encontrar-se e conhecer-se ${ }^{7}$.

7 Apesar dos (pequenos) passos que vêm sendo dados nos planos da oferta formativa e da investigação, a Universidade de Coimbra não pode ainda comparar-se com algumas congéneres americanas e europeias, onde a circulação de saberes se tornou prática especialmente fecunda. 
Inquéritos levados a cabo em algumas universidades europeias parecem comprovar o que já se intuía: que as bibliotecas universitárias gozam de elevado apreço junto das comunidades que servem. Assim sucede também em Coimbra. Ao longo dos 500 anos de vida que comemorámos em 2013, recebemos muitas manifestações de apreço e de carinho. Não faltam, de facto, individualidades nacionais e estrangeiras que associam a Universidade de Coimbra à sua biblioteca, valorizando sobretudo a vertente patrimonial, abrangendo livros, que podem ir desde as farmacopeias mais antigas até atlas de astronomia ou de anatomia, compêndios jurídicos do século XVII ou uma primeira edição de tesouros da Literatura como Os Lusiadas ou a Mensagem.

Mas não falo só de vínculos afetivos, embora estes não devam ser desprezados. Falo também de laços de natureza intelectual e científica, cuja importância justifica atenção e incentivo. Menciono apenas alguns exemplos. A Biblioteca realiza, por ano, uma média de 8 Exposições, algumas delas com Catálogo, versando temas que vão da Arquitetura, à Botânica, à História, etc. Para mencionar apenas casos recentes, invoco uma mostra sobre as relações que se verificaram ao longo de 5 séculos entre Portugal e a China (exposição que promovemos em colaboração com o Museu da Ciência e o Arquivo da Universidade). Seguiu-se imediatamente uma outra, esta incidindo sobre Soren Kierkegaard, que contou com a colaboração da Embaixada da Dinamarca e a participação de Professores de Filosofia. Logo a seguir, montou-se uma mostra sobre a Peregrinação (livro de viagens publicado, pela primeira vez, em 1614 e imediatamente traduzido para as principais línguas europeias). Esta exposição vai ainda ser acompanhada por um Colóquio, dinamizado por um centro de investigação, assinalando os quatrocentos anos da publicação de um dos livros mais importantes da cultura portuguesa.

Em 2015, iniciaremos uma mostra de tesouros bibliográficos, essencialmente destinada à comunidade académica. Aos sábados, de manhã, estará exposto um livro precioso, em suporte impresso e em suporte digital. A explicação da importância do livro estará confiada a um especialista. Terá de ser uma explicação breve e acessível, de modo a que um estudante de Medicina ou de Direito possa compreender o significado de um 
tratado de Filosofia ou de Retórica. Em cada uma dessas sessões, haverá ainda lugar para a intervenção de um bibliotecário, que se ocupará do livro enquanto objeto que "fala" a partir da sua materialidade: o papel de que é feito, os tipos que serviram para a sua impressão, a tipografia onde foi concebido, etc.

Nenhuma destas iniciativas é extraordinária. Ainda assim, pode perguntar-se: poderia qualquer uma delas ter sido promovida por uma Faculdade ou por um Departamento? Sem dúvida que sim. Mas não teria a mesma amplitude e, sobretudo, não teria a mesma transversalidade. Promovidas por uma Secção, um Departamento ou mesmo por uma Faculdade, as exposições de que falei seriam entendidas como eventos que não interessariam à comunidade académica, no seu todo. Realizando-se na biblioteca e com a participação ativa dela, é possível obter uma ampliação de impacto. Concretamente, chama-se melhor a atenção para o facto de o encontro entre o Ocidente e o Oriente não interessar apenas aos historiadores; por outro lado, a evocação do grande filósofo dinamarquês, por ocasião da passagem de duzentos anos sobre o seu nascimento, não deve apenas dizer respeito a um setor do saber. De igual modo, a exibição de um exemplar da primeira edição do livro de Fernão Mendes Pinto chama a atenção de toda a universidade para uma efeméride que não deveria passar despercebida num país que viveu boa parte da sua história sob o signo do mar, da aventura e do contacto com o Oriente. Acolhendo e promovendo manifestações desse género, a Biblioteca Geral cumpre uma missão que outras unidades não podem cumprir tão bem, contribuindo para a irradiação de iniciativas culturais que, embora pertencendo mais a um determinado campo do saber, acabam por convocar todo o campus académico, dando mais sentido à palavra universidade.

Para concluir, permitam que vos fale de uma outra função essencial que a biblioteca universitária é chamada a cumprir nos nossos dias. Refiro-me ao contacto com o livro, enquanto unidade de pensamento e de discurso. Para além das suas metamorfoses materiais, aquilo que melhor caracteriza o livro é justamente o facto de ele constituir uma unidade, imputável a um autor, mesmo quando este é desconhecido. Quer sob a forma de rolo quer sob a forma de codex quer ainda sob formato 
electrónico, o principal oposto do livro continua a ser o fragmento e a informação não validada.

Embora possa também guardar fragmentos (que muitas vezes sobraram de um livro ou não chegaram a transformar-se nele) e também jornais e revistas, mapas, gravuras, fotografias e até peças numismáticas, a biblioteca guarda sobretudo livros $^{8}$.

Todos sabemos que o nosso tempo favorece o extrato, seja em forma de capítulo breve, seja em forma de paráfrase, muitas vezes já desligada do autor. Esta mentalidade, que antes apenas prevalecia no Ensino Secundário, tem vindo a ganhar espaço nas universidades. Mesmo em áreas onde se poderia esperar que a sua implantação pudesse ser mais difícil (penso sobretudo nas ciências sociais e nas humanidades) existem já sinais abundantes dessa tendência. O estudante trabalha hoje em frente de um ecrã (de dimensões cada vez mais reduzidas), aciona motores de busca e cria a ilusão de que os dados que recolhe em pouco tempo e sem esforço de pesquisa representam conhecimento fiável. Sabemos que alguns professores desencorajam energicamente estes procedimentos; mas também sabemos que, ainda que de forma inconsciente, outros vão fazendo concessões que crescem de ano para ano. Basta olhar para a contração das listagens de bibliografia da maior parte das cadeiras. Falo agora apenas das cadeiras de Letras, evocando o meu tempo de aluno, quando os programas eram acompanhados de longas listagens de estudos (na sua maioria, constituídos por livros). Para nosso desgosto, essas listagens nem sequer vinham hierarquizadas?. Penso, depois, no meu tempo de Assistente (correspondendo aos primeiros anos da década de 90), quando me competia guiar os alunos por entre o emaranhado da bibliografia que o Professor indicava, permitindo dispensar a leitura de metade dos livros a quem se contentava com classificações medianas.

\footnotetext{
8 Não se ignora, evidentemente, a valia do fragmento enquanto forma de representação mental e discursiva que detém uma nobre tradição no Ocidente e no Oriente. Mas infelizmente não é por essa "nobre tradição" (que pode ir dos fragmentos de Arquíloco, aos Essais de Montaigne ou aos Propos de Alain) que os estudantes manifestam a sua predileção.

9 Apesar de tudo, recordo que havia exceções. Nesses casos, sempre muito aplaudidos pelos alunos, os itens bibliográficos surgiam precedidos de 1, 2 ou 3 asteriscos, indiciando o seu grau de importância.
} 
As instruções iam sempre, porém, no sentido de criar um remorso forte naqueles que não lessem tudo.

Hoje, todos o sabemos, prevalece uma outra atitude. As bibliografias que figuram nas plataformas digitais são, desde logo, reduzidas por força das limitações de espaço (raramente se consente que o espaço disponível para o elenco de leituras ultrapasse os cinco mil caracteres). Algumas vezes, essas listagens não chegam a ser significativamente ampliadas no decurso das aulas. De cedência em cedência, desistiu-se de levar o aluno a dialogar diretamente com os Mestres, investigadores e ensaístas que escreveram livros inteiros e construíram conhecimento em primeira mão. Alguns procuram ainda esse diálogo. Mas são cada vez em menor número.

Ora, justamente a promoção do contacto com o livro equivale a uma atitude de resistência de grande alcance. Valorizar a obra e não apenas o excerto significa enveredar por uma ética pedagógica, marcada pela exigência e pela perseverança. Estimular o aluno a construir o seu próprio conhecimento é torná-lo capaz de reconstruí-lo em cada momento da sua vida. Esse desiderato requer porventura uma inflexão concertada da atitude dos docentes. Mas será mais bem sucedida se contar com colaboração estreita de bibliotecas apetrechadas e dinâmicas, onde o otimismo deve ultrapassar a melancolia e o desencanto ${ }^{10}$.

Ao contrário do que possa pensar-se, a perversão que resulta desta cultura fragmentária e estritamente informacional não é de hoje. O tempo das sebentas únicas (ainda não totalmente extinto) constitui já uma expressão dessa cultura simplificada e acrítica. Mas não pode esconder-se que, nos últimos anos, a profusão dos suportes digitais tem contribuído para a intensificação das ilusões esquemáticas, envolvendo a substituição do livro inteiro pelos pedaços inorgânicos que aparecem (e desaparecem) no

$10 \mathrm{Na}$ segunda sala da Biblioteca Joanina, a universidade é justamente representada com uma joeira na mão direita, significando a necessidade de que nela subsista a capacidade de distinguir. Trata-se de mais um sinal que, evocando a realidade da época, se repercute nos nossos dias, com evidente atualidade. Já no início do século seguinte, em texto preparado para justificar a fundação da Universidade de Berlim, o filósofo alemão Joachim Fichte, não deixa de apontar como missão crucial da instituição universitária "a arte da crítica, da discriminação entre o verdadeiro e o falso, o útil e o inútil e a subordinação do menos ao mais importante". (Apud LLOVET, Jordi - Adiós a la universidad. El eclipse de las humanidades. Barcelona: Editorial Galaxia Gutenberg, 2011. p. 52). 
ecrã, sem se fixarem na memória e no entendimento ${ }^{11}$. Por último, parece incontestável que a semestralização do período letivo (equivalendo cada semestre a doze semanas de aulas) não favoreceu o tempo de leitura e de maturação. Pelo contrário: confrontado com a necessidade de passar no exame que se realiza apenas três meses depois do início das aulas, o aluno opta sistematicamente pelas sínteses já construídas, abdicando de construir o seu próprio saber a partir de fontes plurais ${ }^{12}$.

4. Apesar de continuarem a ser lugares de eleição para alguns, tem de reconhecer-se que as bibliotecas universitárias se tornaram lugares estranhos para uma parcela considerável de estudantes e de professores ${ }^{13}$. Impõem a observância do silêncio, desde logo, o que significa um forte constrangimento para a maior parte das pessoas que vivem no barulho e no zapping (prática que não é exclusiva das gerações mais novas). Um livro de Física ou um ensaio de Filosofia de 200 páginas podem demorar 5 horas a ler. E bem sabemos que raramente existem 5 horas de concentração consecutiva ou mesmo intercalada na vida de um leitor jovem. Para mais, a leitura desse ensaio requer continuidade, não consentindo suspensões muito longas. Mas isso não é tudo: a seguir a esse ensaio, será preciso ler outros, uma vez que uma característica essencial dos

11 Sobre os efeitos perniciosos que resultam da substituição do livro pelo fragmento digital, vejam-se os lúcidos e bem fundamentados trabalhos de: LARIZZA, Olivier - La querelle des livres. Petit essai sur le livre à l'âge numérique. Paris: Libella, 2012; DARNTON, Robert - L'apologie du livre: demain, aujourd'hui, hier. Paris: Gallimard, 2011 (que, neste mesmo volume, assina outro trabalho notável a esse propósito); e de ROCHE, Florence; SABY, Frédéric, coord. - L'avenir des bibliothèques : l'exemple des bibliothèques universitaires. Villeurbanne: Presses de l'enssib, 2013. pp. 20 e ss.

12 Sobre as alterações verificadas no tempo e na atitude de estudo a partir da entrada em vigor do "Modelo de Bolonha", vejam-se os três estudos que integram o primeiro capítulo do livro coordenado por: ROCHE, Florence; SABY, Frédéric, coord. - L'avenir des bibliothèques: l'exemple des bibliothèques universitaires. pp.11-42.

13 No que toca à Biblioteca Geral da Universidade de Coimbra (que coexiste com mais 20 bibliotecas especializadas, instaladas no mesmo campus), importa dizer que se tem verificado um aumento sustentado da frequência e da requisições de livros. Nos últimos três anos letivos (entre 2010/2011 e 2013/2014), nomeadamente, o volume anual de leitores subiu de 19372 para 22199, tendo o número de obras requisitadas subido ainda mais notavelmente de 20517 para 41826. 
bons livros é o de solicitarem o conhecimento de outros bons livros, num processo entusiasmante mas sem termo.

A circunstância que mais afasta os jovens do contacto com os livros (sobretudo com os livros grandes e difíceis) reside, porém, num outro aspeto menos falado: é que se deixou de insistir na recompensa que pode obter-se com uma tarefa desse tipo. Tratando-se de uma atividade que colide com as tendências naturais (embora reunindo muitos méritos, o livro não deixa de ser uma invenção humana, com tudo o que isso envolve de imperfeição) e com os ritmos instalados na vida dos nossos dias, a leitura de investigação só vale a pena se houver um fim superior que a justifique ${ }^{14}$.

Para as gerações menos jovens, esse fim sempre existiu e sempre se bastou a si próprio. Mas hoje deixou de ser assim. Por isso se revela importante não desistir da moral que faz do livro (seja em que suporte for) um meio insubstituível para se alcançar a recompensa do conhecimento. Refiro-me ao conhecimento precário e humilde, aquele que se reúne num tratado, num ensaio ou num romance que há de ser superado por outros tratados, outros ensaios e outros romances, que nos acompanham e nos ajudam a crescer.

5. Regresso, por fim, à Biblioteca Joanina da qual comecei por vos falar. Quero agora chamar a atenção para um micro-espaço que lá existe e no qual poucos reparam. Penso especificamente nos gabinetes de 3 metros quadrados que se situam à esquerda de quem entra. São pequenos demais para os gostos e os hábitos de hoje mas oferecem outras vantagens: proporcionam vista para o arvoredo e para o rio Mondego e estão equipados com uma cadeira rasa e o tampo inclinado de uma mesa. É necessário entrar e instalarmo-nos para aferirmos de todas as vantagens que nos oferecem: a exiguidade do espaço impõe-nos a concentração no livro que

14 No seu longo ensaio sobre o assunto, Steiner refere duas formas de resistência mental ao livro: o "pastoralismo radical", assente na ideia de que o livro nunca consegue reproduzir a experiência autêntica da realidade, e o utilitarismo niilista, que acentua o facto de o livro não servir de remédio aos grandes males que afetam a espécie humana (STEINER, Georges - Le silence des livres. Paris: Arlea, 2007. pp. 26 e ss.). 
se está a ler. A paisagem permite-nos pequenos intervalos de espírito, tão necessários à assimilação do que se lê; a contemplação do fluir das águas garante-nos o que nunca deveríamos esquecer quando lidamos com o conhecimento: há movimentos que vêm de longe e o tempo continua a correr independentemente dos ruídos do mundo (interior e exterior).

Há estantes mas são pequenas. Ouço dizer que antes eram ainda mais acanhadas. Essa circunstância constitui também um benefício inestimável: impede a dispersão, um dos inimigos mais poderosos da leitura perseverante e atenta.

Pela sua pequenez e pelo ambiente de clausura que evocam, esses gabinetes de investigação lembram os antigos scriptoria, onde se recolhiam os intelectuais eclesiásticos da Idade Média, que dedicavam a vida à leitura e à escrita, sem nenhum tipo de limite.

Gostando orgulhosamente de toda a Biblioteca Joanina, devo confessar que nada me atrai tanto nela como aquele micro-espaço que passa despercebido aos olhares dos turistas, ocupados com outras atrações. Para mim, o pequeno gabinete representa a utopia da investigação operosa e feliz. Ponho-me a pensar em todas as utopias que os homens construíram, grande parte delas plasmadas na literatura e noutras artes (ilhas afortunadas, cidades ideais, fontes de eterna juventude) e dou-me conta de que aquela outra não tem sido suficientemente destacada, como integrando os mais altos ideais de realização humana. Falo justamente da possibilidade de alguém poder suspender o tempo do relógio para se fechar num gabinete, levando consigo apenas os livros de que precisa (nem obras a mais nem a menos). Pode então dedicar-se a escrever outros livros, dando continuidade ao interminável diálogo humano. Enquanto isso, o rio corre, ao alcance da vista, ilustrando esta verdade suprema: a de que, tal como o curso das águas, também a nossa vida, envolvendo dúvidas, sonhos e anseios, teve precedentes, correndo sempre para uma foz, onde tudo se renova e se dissolve. Poderão dizer que me situo no limiar da utopia. Tenho consciência disso mesmo. Mas também sei que as utopias desempenham uma função muito importante no progresso humano: ajudam-nos a compreender o passado e a modelar o presente, combinando ambição e bom senso. O que de mais importante hoje se 
pode pedir à biblioteca talvez seja isso mesmo: combinar essas duas componentes. Nem que para isso seja preciso que tenha de assumir-se como contraponto (ou, pelo menos, como intervalo) à fragilização da ética na pesquisa e à aceleração do tempo mundano.

À luz destes pensamentos, inspirado pela figuração inscrita no teto da segunda sala, o mesmo em que a universidade aparece rodeada pelos valores da Honra e da Virtude, parece realmente possível opor alguma resistência à futilidade, à precipitação e ao ruído. Convenço-me então (quero convencer-me) de que, hoje como há trezentos anos, ainda não existe melhor alegoria para a universidade do que uma biblioteca rica e bem apetrechada. Não podem faltar terminais de computador. Não pode faltar a preocupação com os vários tipos de utente: os que querem ver um manuscrito do século XIII ou os que pretendem requisitar um "e-book". Será muito aconselhável também que nela exista um espaço agradável, onde os leitores possam encontrar-se para tomar um café e falar de vários assuntos, desde os mais triviais aos mais elevados.

Terá de haver tudo isso na biblioteca da universidade. Mas acima de qualquer serviço antigo ou moderno, a biblioteca tem de continuar a ser um lugar de paz, de curiosidade e de encontro. Permitam que insista num requisito final: sendo possível, não devem faltar janelas abertas e vista para um rio.

\section{Referências bibliográficas}

AmAral, António Eugénio Maia, (coord.) - Os livros em sua ordem. Para a bistória da Biblioteca da Universidade de Coimbra. Coimbra, Imprensa da Universidade, 2014.

BARBIER, Frédéric - Histoire du livre. 2. ${ }^{\mathrm{a}}$ ed. Paris: Armand Colin, 2009.

BARBIER, Frédéric - Histoire des bibliothèques: d'Alexandrie aux bibliothèques virtuelles. Paris: Armand Colin, 2013.

CRUZEIro, Maria Eduarda - A reforma pombalina na história da Universidade. Análise Social. ISSN 0003-2573. 24:100 (1988) 165-210. 
DARNTON, Robert - L'apologie du livre: demain, aujourd'hui, hier. Paris: Gallimard, 2011.

FIOlHAis, Carlos e MENDES, Paulo - A Biblioteca Joanina. Coimbra. Imprensa da Universidade, 2013.

FONSECA, Fernando Taveira da - A Universidade de Coimbra (1700-1771). Estudo social e económico. Coimbra: Por ordem da Universidade, 1995.

LARIZZA, Olivier - La querelle des livres. Petit essai sur le livre à l'âge numérique. Paris: Libella, 2012.

LLOVET, Jordi - Adiós a la universidad. El eclipse de las humanidades. Barcelona: Editorial Galaxia Gutenberg, 2011.

KAGAN, Jerome - The three cultures: Natural Sciences, Social Sciences and the Humanities in the $21^{\text {st }}$ Century. Cambridge: Cambridge University Press, 2009.

ROCHE, Florence; SABY, Frédéric, coord. - L'avenir des bibliothèques: l'exemple des bibliothèques universitaires. Villeurbanne: Presses de l'enssib, 2013.

STEINER, Georges - La Haine du livre. Esprit. Paris. Jan. 2005.

STEINER, Georges - Le silence des livres. Paris: Arlea, 2007. 
José Augusto Cardoso Bernardes é Professor da Faculdade de Letras da Universidade de Coimbra e Diretor da Biblioteca Geral da Universidade

Ana Maria Eva Miguéis é coordenadora do Serviço Integrado das Bibliotecas da Universidade de Coimbra

Carla Ferreira é bibliotecária nos Serviços de Biblioteca e Documentação da Faculdade de Letras da Universidade de Coimbra. 


\section{Série Documentos}

Imprensa da Universidade de Coimbra

Coimbra University Press

2015

C •

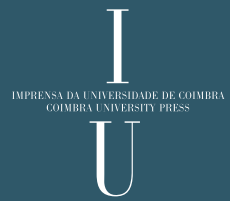

